\title{
Acyclovir (Zovirax) in herpetic disciform keratitis
}

\author{
L. M. T. COLLUM, ${ }^{1}$ P. LOGAN,${ }^{1}$ AND T. RAVENSCROFT ${ }^{2}$ \\ From the ${ }^{1}$ Royal Victoria Eye and Ear Hospital, Dublin, and ${ }^{2}$ Wellcome Research Laboratories, Kent
}

SUMMARY Forty patients with disciform keratitis were randomly assigned to double-blind treatment with $3 \%$ acyclovir and $0.01 \%$ betamethasone drops or acyclovir and matching placebo. All patients who received the combination healed in a median time of 21 days, while 11 of 19 patients who received acyclovir alone were withdrawn because their condition remained static or worsened $(p<0.001)$. The combination therapy produced a faster rate of healing $(p=0.004)$; other clinical parameters also improved more favourably in the combination treatment group. Three patients had mild transient punctate keratopathy, but no serious adverse effects were seen despite treatment for a median duration of 28 days in the acyclovir group and 38 days in the combined therapy group. A combination of acyclovir and dilute steroid drops is effective in the management of disciform keratitis.

Acyclovir is an effective antiherpetic agent with a selective action in herpes infected cells. ${ }^{12}$ Since the first demonstration of a clinical antiviral effect in the eye $^{3}$ acyclovir has been shown to be at least as effective $^{4}$ or more effective ${ }^{56}$ than idoxuridine and adenine arabinoside ${ }^{7 \rightarrow}$ and broadly equivalent to trifluorothymidine in the treatment of dendritic corneal ulceration. ${ }^{10}$ Therapy with acyclovir has been associated with a low incidence of mild, transient adverse effects, namely stinging and punctate keratopathy. Patients failing to respond to other antiviral agents have shown favourable clinical responses to acyclovir in open evaluation. ${ }^{1 "}$

Stromal keratitis is a more serious herpes infection of the cornea which has a longer clinical course and is often difficult to treat. Two forms of this infection can be recognised. Necrotising stromal keratitis, usually associated with and found under dendritic ulceration, is associated with significant corneal melting and a yellowish necrotic appearance. In this case it is almost certain that direct viral invasion occurs, causing the observed pathology. This should be distinguished from the disease referred to as disciform keratitis or oedema. It is different in appearance, and immune mechanisms probably play a significant part in its aetiology. Patients with disciform keratitis and iritis have been shown to have viral antigen in the white cells of the anterior chamber together with cell-free virus, although it has been difficult to culture virus Correspondence to Mr L. M. T. Collum, 9 Fitzwilliam Place. Dublin 2. from the aqueous humour. ${ }^{12}$ While the aetiology of disciform keratitis is unclear, it is known that small doses of corticosteroids will suppress and control the disease. However, the possible involvement of replicating virus suggests that an antiviral drug which can reach therapeutic levels in the aqueous humour should also be used.

While a combination of antiviral and steroids would seem to be the optimal therapeutic choice, it is important to determine whether an antiviral drug alone could offer a similar degree of therapeutic response, avoiding the problems associated with steroid use.

Acyclovir is a good candidate for the role as it is able to penetrate the intact corneal epithelium and stroma, achieving therapeutic levels in the aqueous humour, unlike other currently available antiviral agents. ${ }^{13}$ The current study was therefore undertaken to investigate the efficacy and safety of topical acyclovir alone or in combination with dilute steroid drops in the treatment of herpetic disciform keratitis.

\section{Materials and methods}

Forty patients with a clinical diagnosis of disciform keratitis were included in the study if they were able to attend regularly for follow-up. Informed consent to participation in the study was obtained from all patients or parents of patients as appropriate. Uniocular patients were excluded. Diagnosis was based on the history and clinical appearance of 
patients; at all visits a full ocular examination was carried out. Patients were seen by the same 2 observers as often as clinically necessary but at least twice weekly during treatment.

All patients received 3\% acyclovir ophthalmic ointment and in addition were randomly assigned to treatment with $0.01 \%$ betamethasone drops or a matching placebo in a double-blind manner. Treatment was applied to the infected eye 5 times daily. Patients also received $1 \%$ homatropine drops and the eye was not padded. If patients showed deterioration over the first 5 days or remained static for 14 days they were withdrawn from the study and treated with an alternative antiviral and a dilute steroid preparation in the usual manner. The keratitis was regarded as healed when the corneal thickness had returned to normal, when epithelial and stromal oedema had regressed, when endothelial deposits were either old in appearance or had disappeared, and when there was no more activity of any kind in the anterior chamber. Corneal thickness was measured with a pachometer attached to the HaagStreit slit-lamp. Symptoms of pain, photophobia, lacrimation, and grittiness were scored at each visit on a 4 -point scale $(0=$ absent, $1=$ mild, $2=$ moderate, $3=$ severe). A record was made of any adverse events potentially attributable to treatment, including assessment of intraocular pressure.

The $t$ test was used to compare treatment groups for age, initial corneal thickness, and initial scores for uveitis, pain, grittiness, lacrimation, and photophobia. The duration of the current attack was compared between treatment groups by the MannWhitney $U$ test because of non-normal distribution. The proportion of patients who received antiviral or steroid therapy for the current attack prior to entry into the study, the proportion with previous ocular infection and with current epithelial infection were compared by Fisher's exact test.

\section{Results}

Nineteen patients were treated with acyclovir and placebo while 21 received acyclovir and dilute steroid drops. Demographic comparison of the treatment groups showed no significant differences at the $10 \%$ level (2-tailed test), except the proportion who had previous antiviral therapy for the current attack $(p=$ $0 \cdot 058$ ). Four of the acyclovir plus placebo group and 5 of the acyclovir plus steroids group had received steroids for previous attacks. These results are presented in Table 1.

All patients who received acyclovir and steroids healed in a median time of 21 days, while 11 of 19 patients who received acyclovir and placebo were withdrawn from the study (Fig. 1), a highly significant

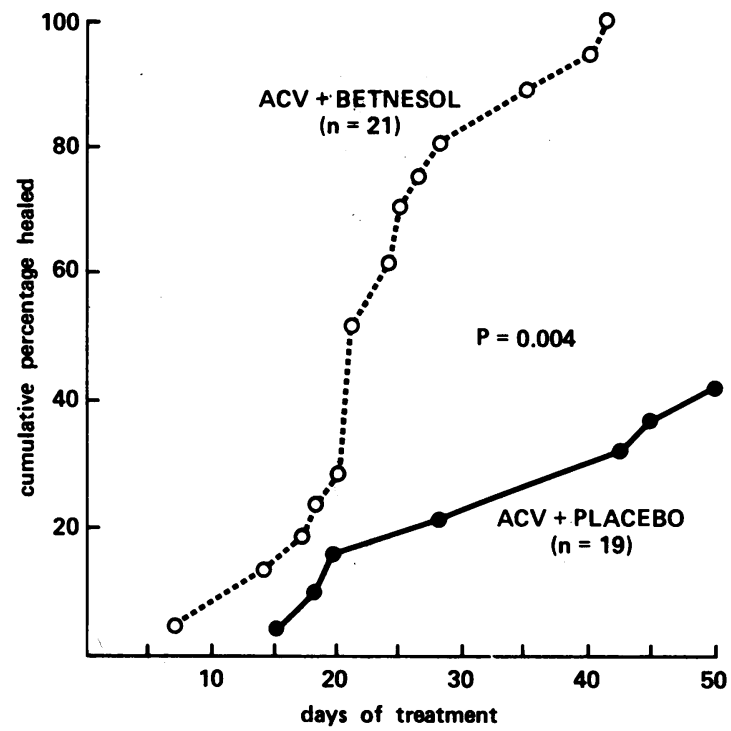

Fig. 1 Cumulative healing rate for patients with disciform keratitis. (Betnesol=betamethasone).

difference $(p<0 \cdot 001$, Fisher's exact test). To avoid possible bias due to the problems associated with withdrawal of steroid therapy in these patients the analysis was repeated after exclusion of 3 patients in the combined therapy group and 5 patients in the group which received acyclovir alone who were receiving steroids at entry. The remaining 18 recipients of the combined therapy who were not receiving steroids at entry healed, while 6 of 14

Table 1 Patient demography

\begin{tabular}{|c|c|c|}
\hline Parameter & $\begin{array}{l}\text { Acyclovirt } \\
\text { placebo } \\
\text { (mean and } \\
\text { standard error) }\end{array}$ & $\begin{array}{l}\text { Acyclovir+ } \\
\text { betamethasone }\end{array}$ \\
\hline Age & $38.9 \pm 3.99$ & $40 \cdot 3 \pm 3 \cdot 57$ \\
\hline Corneal thickness & $2 \cdot 11 \pm 0 \cdot 215$ & $2 \cdot 25 \pm 0 \cdot 204$ \\
\hline Uveitis: flare & $1 \cdot 11 \pm 0 \cdot 186$ & $0 \cdot 76 \pm 0 \cdot 153$ \\
\hline cells & $0 \cdot 84 \pm 0 \cdot 175$ & $0 \cdot 62 \pm 0 \cdot 146$ \\
\hline Symptoms (0-3): Pain & $0 \cdot 79 \pm 0 \cdot 244$ & $0 \cdot 55 \pm 0 \cdot 211$ \\
\hline grittiness & $0.95 \pm 0.223$ & $0 \cdot 90 \pm 0 \cdot 161$ \\
\hline photophobia & $1 \cdot 47 \pm 0 \cdot 280$ & $1 \cdot 55 \pm 0 \cdot 235$ \\
\hline lacrimation & $1 \cdot 26 \pm 0 \cdot 290$ & $0 \cdot 75 \pm 0 \cdot 260$ \\
\hline $\begin{array}{l}\text { Duration of symptoms } \\
\text { (median weeks) }\end{array}$ & & \\
\hline $\begin{array}{l}\text { (median weeks) } \\
\text { Previous antiviral therapy for }\end{array}$ & 4 & 2 \\
\hline $\begin{array}{l}\text { current attack } \\
\text { Previous steroid therapy for }\end{array}$ & 12 of 19 & 7 of 21 \\
\hline current attack & 5 of 19 & 3 of 21 \\
\hline $\begin{array}{l}\text { Previous ocular infection } \\
\text { Previous steroid therapy for }\end{array}$ & 13 of 19 & 11 of 21 \\
\hline previous attack & 4 of 19 & 5 of 21 \\
\hline Current epithelial infection & 7 of 19 & 5 of 21 \\
\hline Sex: Male & 12 & 10 \\
\hline Female & 7 & 11 \\
\hline
\end{tabular}


Table 2 Progression of corneal thickness and uveitis

\begin{tabular}{ccc}
\hline & $\begin{array}{l}\text { Acyclovirt } \\
\text { placebo } \\
(n=19)\end{array}$ & $\begin{array}{l}\text { Acyclovirt } \\
\text { betamethasone } \\
(n=21)\end{array}$ \\
\hline Corneal thickness: same & $8^{*}$ & $1^{*}$ \\
better & 8 & 20 \\
worse & 3 & 0 \\
Uveitis: same (flare/cells) & $11 / 12$ & $0 / 0$ \\
better (flare/cells) & $7 / 5$ & $21 / 21$ \\
worse (flare/cells) & $1 / 1$ & $0 / 0$ \\
\hline
\end{tabular}

*One patient normal at entry.

recipients of acyclovir and placebo who had not received steroids at entry failed to respond $(p<0 \cdot 007$, Fisher's exact test). Of the 14 acyclovir and placebo recipients 2 had a history of steroid treatment for previous attacks. One of these healed while the other failed to respond.

In addition the rate of healing was analysed for the groups and compared by logrank analysis. Patients receiving acyclovir and steroids healed at a significantly faster rate $(p<0.004)$.

Clinical parameters which tend to be responsive to steroid therapy include uveitis and corneal thickness. The improvement in both of these parameters by the end of therapy was particularly marked in the group which received acyclovir and betamethasone. A formal analysis of these parameters was not possible because of the large proportion of acyclovir and placebo recipients who were withdrawn before they healed. From the results presented in Table 2 it can be seen that all patients who received acyclovir and betamethasone had returned to normal: In the group which received acyclovir and placebo 3 patients had increased corneal thickness and one had more severe uveitis at the end of therapy.

Twenty-seven of the 40 patients included in the study had a visual acuity less than $6 / 18$ (Table 3 ). The change in visual acuity during therapy was similar for both groups. However, visual acuity worsened in 4

Table 3 Visual acuity

\begin{tabular}{lll}
\hline & $\begin{array}{l}\text { Acyclovirt } \\
\text { placebo } \\
(n=19)\end{array}$ & $\begin{array}{l}\text { Acyclovirt } \\
\text { betamethasone } \\
(n=21)\end{array}$ \\
\hline $\begin{array}{l}\text { Visual acuity at } \\
\text { presentation: }\end{array}$ & \\
$\quad 6 / 60$ & 3 & \\
$6 / 60$ & 5 & 2 \\
$6 / 18$ & 6 & 9 \\
$6 / 9$ & 5 & 8 \\
Change in visual acuity after & & \\
therapy: & & \\
$\quad$ Same & 10 & 12 \\
Better & 5 & 8 \\
Worse & 4 & 1 \\
\hline
\end{tabular}

recipients of acyclovir and placebo and one recipient of acyclovir and betamethasone.

Symptoms of pain, photophobia, lacrimation, and grittiness had completely resolved in 20 of 21 acyclovir and betamethasone recipients. In contrast, only 9 of 19 acyclovir and placebo treated patients had a similar response, but it should be kept in mind that a large proportion of these patients left the study with active disciform keratitis.

Treatment continued for an average of 28 days in the acyclovir and placebo group and an average of 38 days in the acyclovir and betamethasone group. The only adverse event recorded was mild, transient punctate keratopathy in 3 patients.

\section{Discussion}

This clinical trial has provided a clear demonstration of the need for a combination of antiviral agent and steroid in the management of disciform keratitis. It is widely accepted that steroids alone cannot be used to treat this herpetic infection because of the danger of further or enhanced virus activity. The 8 patients who responded to acyclovir alone may represent the proportion of cases which might be expected to make a full recovery, in the absence of further virus activity, without therapeutic intervention.

It is unfortunate that in these patients it is not possible to avoid the use of steroid therapy and the problems associated with it. However, acyclovir combined with $0.01 \%$ betamethasone drops has been shown to produce a rapid and consistent clinical response with virtually no adverse effects. We therefore conclude that acyclovir combined with steroids is more effective than acyclovir alone, and that acyclovir without concomitant steroids does not provide effective control of disciform keratitis.

We thank Mrs C. Burke, medical statistician, Wellcome Research Laboratories, for carrying out the statistical analysis of this clinical trial.

\section{References}

1 Elion GB, Furman PA, Fyfe JA, et al. Selectivity of action of an antiherpetic agent 9-(2-hydroxyethoxymethyl)-guanine. Proc Natl Acad Sci USA 1977; 74: 5716-20.

2 Schaeffer HJ, Beauchamp L, de Miranda P, Elion GB. 9-(2hydroxyethoxymethyl)-guanine activity against viruses of the herpes group. Nature 1978; 272: 583-5.

3 Jones BR, Coster DJ, Fison PN, et al. Efficacy of acycloguanosine (Wellcome 248U) against herpes simplex corneal ulcers. Lancet 1979 ; i: $243-4$.

4 Coster DJ, Wilhelmus KR, Michand R, Jones BR. A comparison of acyclovir and idoxuridine as treatment for ulcerative herpetic keratitis. Br J Ophthalmol 1980; 64: 763-765.

5 Collum LMT, Benedict-Smith A, Hillary IB. Randomised double blind trial of acyclovir and idoxuridine in dendritic corneal ulceration. Br J Ophthalmol 1980; 64: 766-9. 
6 Colin J, Tournoux A, Chastel C, Renard G. Superficial herpes simplex keratitis, double blind comparative trial of acyclovir and idoxuridine. Nouv Presse Med 1981; 10: 2969-75.

7 Pavan-Langston D, Lass J, Hettinger M, Udell I. Acyclovir and vidarabine in the treatment of ulcerative herpes simplex keratitis. Am J Ophthalmol 1981; 92: 829-35.

8 McGill J, Tormey P, Walker CB. Comparative trial of acyclovir and adenine arabinoside in the treatment of herpes simplex corneal ulcers. Br J Ophthalmol 1981; 65: 610-3.

9 Young B, Patterson A, Ravenscroft T. A randomised double blind clinical trial of acyclovir (Zovirax) and adenine arabinoside in herpes simplex corneal ulceration. Br J Ophthalmol 1982; 66: 361-3.
10 la Lau C, Oosterhuis JA, Versteeg J, et al. Multicentre trial of acyclovir and trifluorothymidine in herpetic keratitis. $\mathrm{Br} J$ Ophthalmol in press.

11 Collum LMT, Benedict-Smith A. Acyclovir (Zovirax) in herpes simplex keratitis. In: Herpetische Augener Krankungen, Freiburg 1980. Munich: Bergman, 1981: 323-7.

12 Kaufman HE. Herpetic stromal disease. Am J Ophthalmol 1975; 80: 1092-4.

13 Sundmacher R. A clinico-virologic classification of herpetic anterior segment diseases with special reference to intraocular herpes. In: Herpetische Augener Krankungen, Freiburg 1980. Munich: Bergman, 1981: 203-10. 